\title{
EDUCAÇÃO SEXUAL NO CONTEXTO FAMILIAR E ESCOLAR: IMPASSES E DESAFIOS
}

\author{
R. C. Gonçalves ${ }^{1}$, J. H. Faleiro ${ }^{2}$, G. Malafaia ${ }^{3}$
}

'Docente do Colégio Estadual Professor Ivan Ferreira, Pires do Rio, GO, Brasil. ${ }^{2}$ Acadêmico do curso de Licenciatura em Química do Instituto Federal Goiano - Câmpus Urutaí, GO, Brasil; ${ }^{3}$ Professor do Departamento de Ciências Biológicas do Instituto Federal Goiano - Câmpus Urutaí, Coordenador do PIBID/CAPES - Subprojeto de Ciências Biológicas e Pesquisador do Núcleo de Pesquisa em Ciências Ambientais e Biológicas.

E-mail: guilhermeifgoiano@gmail.com ${ }^{3}$

Artigo submetido em dezembro/2011 e aceito em outubro/2013

\section{RESUMO}

O presente artigo é resultado de uma revisão da literatura e tem como objetivo abordar os impasses e desafios no desenvolvimento da educação sexual por parte de pais e educadores, bem como discutir o valor da educação sexual emancipatória na formação dos jovens. Os resultados evidenciados a partir de diferentes estudos demonstram que muitas famílias privam seus filhos da educação sexual emancipatória, pelo valor negativo atribuído a sexualidade, por acreditarem que os filhos são "seres assexuados", por considerarem que o diálogo antecipa a prática sexual e por se sentirem despreparados e tímidos em tratar do assunto oriundo da deseducação sexual na qual foram vítimas. Evidenciou-se que nas escolas a educação sexual não tem abarcado as ansiedades dos adolescentes. Contrariamente, esta tem ocorrido de forma limitada, aliada, sobretudo, aos aspectos biológicos e reprodutivos do indivíduo, negando assim, toda a amplitude prazerosa e benéfica que a mesma propicia. Conclui-se, portanto, que maior atenção deve ser dada à temática sexualidade e sua abordagem nas escolas e nas relações entre pais e filhos. Maior aproximação entre pais, filhos e escolas mostra-se como importante estratégia e ser adotada, assim como o estímulo a debates nas instituições educacionais, consideradas espaços privilegiados para a aprendizagem e realização de reflexões de temas socialmente relevantes.

PALAVRAS-CHAVE: Sexualidade, adolescência, educação, escola.

\section{SEXUAL EDUCATION, FAMILY AND SCHOOL: CHALLENGES AND IMPASSES}

\begin{abstract}
This article is the result of a literature review and aims to address the challenges and dilemmas in the development of sexual education by parents and educators, as well as discussing the value of emancipatory sexual education in youth training. The results shown from different studies evidenced that many families deprive their children of emancipatory sexual education, the negative value sexuality, believing that children are "asexual beings", as they believe that dialogue anticipated sexual practice and is feel unprepared and timid in dealing with the issue arising from the sexual uneducated in which they were victims. Showed that sexual education in schools has spanned
\end{abstract}

the anxieties of adolescents. In contrast, this has occurred in a limited way, coupled mainly to biological and reproductive aspects of the individual, thus negating the whole breadth pleasurable and beneficial that it provides. We conclude, therefore, that more attention should be given to their sexuality and thematic approach in schools and in the relations between parents and children. Closer relationship between parents, children and schools shows itself as an important strategy and be adopted as well as the stimulus debates in educational institutions, considered as privileged spaces for learning and performing reflections of socially relevant themes.

KEYWORDS: Sexuality, adolescence, education, school. 


\section{EDUCAÇÃO SEXUAL NO CONTEXTO FAMILIAR E ESCOLAR: IMPASSES E DESAFIOS}

\section{INTRODUÇÃO}

A adolescência é um período do desenvolvimento humano marcada por intensas transformações biopsicossociais estimuladas pela ação hormonal característica da puberdade. A adolescência constitui uma fase de transição entre a infância e a condição de adulto, em que se observa um acentuado amadurecimento corporal, significativas transformações emocionais, construção de novas relações interpessoais, manifestações de novos sentimentos, atitudes, decisões, as quais resultam na construção de uma identidade própria (OLIVEIRA et al., 2009). Entre as modificações que se apresentam na adolescência, destacam-se aquelas relacionadas ao desenvolvimento da sexualidade.

O sentir-se bem no âmbito da sexualidade constitui um dos principais critérios de saúde mental e de satisfação interpessoal (SIQUEIRA, 2001). Assim, tem sido percebida nos últimos anos a necessidade do envolvimento da família e da escola no processo de educação sexual dos adolescentes, nomeadamente pelo fato deste envolvimento proporcionar esclarecimentos e reflexões para que os jovens desfrutem a sua sexualidade de maneira saudável e responsável. 0 grande desafio da educação sexual é contribuir para que os jovens exponham suas dúvidas e as esclareçam, superem preconceitos e estereótipos e desenvolvam atitudes saudáveis relacionados à sexualidade.

De acordo com Souza (1991), educar sexualmente consiste em oferecer condições para que as pessoas assumam seu corpo e sua sexualidade com atitudes positivas, livres de medo, preconceitos, culpas, vergonha, bloqueios ou tabus. Conforme ressaltado por ECOS - Estudos e Comunicação em Sexualidade e Reprodução Humana (ECOS, 2013), a educação sexual deve ser entendida como um direito que as crianças e/ou adolescentes têm de conhecer seu corpo e ter uma visão positiva da sua sexualidade; de manter uma comunicação clara em suas relações; de ter pensamento crítico; de compreender seu próprio comportamento e o do outro. Deve ser preocupação dos pais e educadores que os adolescentes tenham uma educação sexual sadia, pautado em valores e hábitos condizentes com a valorização da vida e com os direitos humanos.

Frente ao exposto, a família e a escola, corresponsáveis pela formação do indivíduo, deve possibilitar aos jovens uma educação sexual que, pressupõe a busca de uma sexualidade emancipatória, ou seja, uma sexualidade gratificante, socialmente livre e responsável, subjetivamente enriquecedora concebida como parte integrante e essencial da vida humana. A educação sexual emancipatória pressupõe o desenvolvimento de ações educativas com a finalidade de promover a autonomia, buscando superar padrões de comportamentos hierarquizados e estereotipados, superando preconceitos e tabus (GARCIA, 2005).

Em nossa sociedade, a sexualidade não tem sido explorada e/ou dialogada de modo que as pessoas sejam educadas a conhecê-la e aprender que o seu exercício não é feio e pecaminoso, culminando, nesse sentido, em uma deseducação sexual. O "não dialogar", desse modo, facilita a exposição de adolescentes a situações de riscos relacionados ao exercício da sexualidade, como gravidez indesejada, contágio de infecções sexualmente transmissíveis e traumas psicológicos e emocionais resultantes da vivência de uma sexualidade frustrante (TRINDADE \& BRUNS, 1999).

Estudos em educação sexual, no contexto familiar e escolar, são de fundamental importância, pois visam a refletir como ela é conduzida e trabalhada na família e na escola. A 
relevância de estudos em torno da temática "sexualidade" pauta-se na contribuição de informações que possam auxiliar pais e educadores no desenvolvimento de uma educação sexual contextualizadora e contemporânea. A identificação das limitações dos pais e professores para a educação sexual adequada pode contribuir para a melhoria desse processo (CHAVES et al., 2004). Desta forma, este trabalho, por meio de uma revisão da literatura, objetivou abordar os impasses e desafios no desenvolvimento da educação sexual por parte de pais e educadores, bem como discutir o valor da educação sexual na formação dos jovens.

\section{MATERIAL E MÉTODOS}

Este trabalho trata-se de um estudo documental. Para a sua realização, foram consultados diferentes documentos (livros, resumos, teses, dissertações e artigos científicos) que abordaram aspectos ligados à educação sexual no contexto familiar e escolar. Especificamente, para a busca dos artigos científicos, os bancos de dados LILACS-BIREME, MEDLINE, SciELO e PubMed foram consultados e os seguintes descritores de pesquisa (palavras-chave e/ou delimitadores), escritos em português e em inglês, separados ou em conjunto, foram utilizados: "educação sexual"; "sexualidade", "família" e "escola". O período da pesquisa foi compreendido entre os meses de junho e julho de 2011.

No que se refere aos artigos científicos consultados, inicialmente foi realizada uma leitura do resumo do trabalho e, se enquadrando na temática do estudo, o mesmo era selecionado e posteriormente lido na íntegra pelos autores.

\section{RESULTADOS E DISCUSSÕES}

\section{Sexualidade e adolescência: considerações iniciais}

Pode-se dizer que a sexualidade, no contexto brasileiro, ainda tem sido considerada um tabu permeado de princípios morais e preconceitos, em que crianças e adolescentes se sentem reprimidos em expor as suas dúvidas e expectativas em relação ao assunto. Talvez a maior dificuldade das famílias em lidar com a sexualidade, está ligada ao fato da sociedade associá-la à obscenidade, a algo sujo, pecaminoso e proibido (MOIZÉS \& BUENO, 2010). É importante considerar que a educação sexual deve ser feita de forma a construir conhecimentos desprovidos de qualquer tipo de ideia que a alie a sexualidade à impureza ou coisa pecaminosa.

Estudos como os realizados por Gir et al. (2000) e Gonçalves et al. (2010), têm demonstrado que na nossa cultura, a sexualidade tem sido associada exclusivamente ao sexo com significado de ato sexual. Apesar de muitas pessoas confundirem o conceito de sexualidade com o do sexo propriamente dito, a sexualidade não se restringe as práticas sexuais. O sexo é apenas um dos aspectos da sexualidade e, para Vitiello (1997), talvez nem mesmo o mais importante.

Mas o que vem a ser a sexualidade? Segundo a Organização Mundial da Saúde (OMS), a sexualidade é uma energia que motiva para encontrar amor, contato, ternura e intimidade; integra-se no modo como nos sentimos, movemos, tocamos e somos tocados; é ser-se sensual e ser-se sexual (OMS, 1990). A sexualidade ultrapassa os aspetos biológicos e reprodutivos. Ela é parte integrante da personalidade e envolve todo o comportamento do indivíduo e expressa-se 
numa diversidade grande de manifestações, tais como: carícias, beijos, abraços, olhares, sentimentos, afetos, fantasias, desejos, sonhos e prazer (SANTOS, 2001). "A sexualidade se manifesta, então, a todo o momento, em todo e qualquer espaço em que o sujeito, meninos $e$ meninas, homens e mulheres, está inserido" (JESUS, 2007, p. 190).

Um aspecto importante para que a sexualidade seja entendida refere-se à conceituação da adolescência. Sobre este aspecto diferentes estudos foram desenvolvidos. No rol destes trabalhos incluem aqueles ligados à antropologia, como o trabalho de Mead (1945), que já questionava a universalidade dos conflitos vividos na adolescência e evidenciava que a adolescência acontece de diferentes formas nas mais variadas culturas; aqueles com enfoque na crise de identidade vivenciada pelos adolescentes, com destaque para a teoria de Erik Erikson (ver detalhes em Suárez (2005)); aqueles relacionados à forma como encarar a adolescência (RAPPAPORT, 2001) e outros como os de Araújo (1993), Wusthof (1994) e Huerre (1998), os quais exploraram as características dos adolescentes e os seus comportamentos sociais e psicoemocionais.

Segundo Araújo (1993), o/a adolescente vivencia três grandes perdas nesse período: a perda do corpo infantil; a perda do papel e da identidade (infância) e a perda dos pais da infância. Ainda de acordo com o autor, as mudanças corporais e psicológicas ocorridas nesse período são intensas e rápidas; as quais chegam acompanhada de uma mudança de identidade que leva o adolescente a uma nova relação com o mundo. Para Wusthof (1994), a adolescência compreende todo o tempo necessário para que a criança se transforme em adulto, em termos biológicos, psíquicos e sociais. Este somente deixará de ser adolescente quando adquirir sua independência socioeconômica, ou seja, quando não depender mais de seus pais para sua sobrevivência. Segundo Wusthof (1994), deve-se entender a adolescência como uma fase seguida de construção cultural que se modifica e se constrói dependendo dos costumes da sociedade em que está inserida. Huerre (1998) destaca que na adolescência, as pessoas devem estabelecer ligações novas entre si e os outros, entre suas representações do mundo de ontem e aquelas das quais se tem necessidade para o amanhã.

Outro aspecto também relacionado à adolescência e à sexualidade, embora não seja foco deste estudo, refere-se à temática gênero como construções culturais. Apenas como exemplificação, citam-se os estudos de Medrado (1997), Medrado \& Lyra (2008), e Nascimento \& Fonseca (2011). Enquanto os dois primeiros enfocam diálogos entre masculinidade e produções feministas, como marcos conceituais de gênero, Nascimento \& Fonseca (2011) oferecerem um bom referencial reflexivo sobre o processo de construção, negociação e reconstrução de feminilidades e masculinidades como construções de gênero. Inspirado nas tramas apresentadas em alguns filmes da obra de Pedro Almodóvar, Nascimento \& Fonseca (2011) oferecem uma reflexão crítica sobre a cristalização das fronteiras entre o que convencionalmente denominamos de "feminino" e "masculino".

\section{Significados diversos da educação sexual e o papel dos pais}

É importante entender que a educação sexual, não significa a exploração apenas de conceitos e exemplos sobre sexo ou desejos sexuais. Quando se fala em sexualidade, pressupõese falar de intimidade e de relações afetivas (MOIZÉS \& BUENO, 2010), haja vista, que a mesma pressupõe afeto, intimidade, emoção, sentimento e bem-estar. Logo, para desenvolver uma educação sexual eficaz é importante considerar que ela não se restringe ao ato sexual. É 
desejável que a educação sexual aborde a sexualidade dentro de um enfoque sociocultural, abrangendo a saúde reprodutiva, as relações de gênero, as relações interpessoais, o prazer corporal e a autoestima, uma vez que, ela tem uma dimensão histórica, cultural, ética e política que abrange todo o ser: corpo e espírito, razão e emoção (SANTOS, 2001).

A ausência da educação sexual no ambiente familiar é mantida porque nela permanece a ideia de filhos "assexuados" (TIBA, 1994; TRINDADE \& BRUNS, 1999). Embora nossa civilização tenha, nos últimos anos, vivido alguns momentos de maior liberalidade em relação aos comportamentos sexuais dos jovens, a sexualidade ainda é considerada exclusiva do mundo adulto e isso significa um controle do exercício da sexualidade das crianças ${ }^{1}$ e adolescentes.

No que concerne à educação das crianças, é importante salientar que, há um claro intuito dos adultos de afastar e reprimir rigorosamente todos os gestos e manifestações sexuais das mesmas. As crianças recebem, desde cedo, uma qualificação ou "julgamento" do mundo adulto em que está imersa, permeado de valores e crenças que são atribuídos à sua busca de prazer (BRASIL, 1997), tida como inadequadas para a idade. Há uma forte tendência dos adultos de reagir de forma a reprimir e ocultar os primeiros movimentos exploratórios que as crianças fazem em seu corpo e aos jogos sexuais com outras crianças, visando à manutenção da sua pureza isentas de pensamentos obscenos. Portanto, não existe nenhuma intenção de educar para o exercício da sexualidade, mas sim para a repressão da sexualidade (BERNARDI, 1985). Para Tiba (1994), esse comportamento não poderia ser diferente, uma vez que nossa educação sempre foi influenciada fortemente pela igreja católica, a qual teve papel importante nesse mecanismo de repressão e sonegação de informações sexuais aos jovens, em particular as crianças.

Uma temática de relevância significativa sobre a educação sexual refere-se à sua abordagem num contexto emancipatório. Diversos autores como Vasconcelos (1971), Nunes (1996), Gagliotto (2009), Tuckmantel (2009) e Gagliotto \& Lembeck (2011) sugerem refletir sobre a construção da sexualidade com o viés da educação sexual emancipatória, ou seja, aquela que possibilita compreender a sexualidade de uma forma que não seja estritamente biológica, mas, sim, abrangente.

Para Vasconcelos (1971), educação sexual emancipatória:

[...] é abrir possibilidades, dar informações sobre os aspectos fisiológicos da sexualidade, mas principalmente informar sobre suas interpretações culturais, e suas possibilidades significativas, permitindo uma tomada lúcida de consciência. É dar condições para o desenvolvimento contínuo de uma sensibilidade criativa em seu relacionamento pessoal. Uma aula de educação sexual deixaria de ser apenas um aglomerado de noções estabelecidas de biologia, de psicologia e moral, que não apanha a sexualidade naquilo que the pode dar significado e vivência

\footnotetext{
${ }^{1}$ Embora o presente trabalho possua como foco os adolescentes, considera-se relevante ressaltar que as crianças fazem parte do processo de construção da sexualidade. Conforme discutido por Dunaigre (2003), as crianças são sujeitos sexuados, dotadas de capacidades específicas para compreender e aprender. Em sua fase seguinte de desenvolvimento, a puberdade, as crianças necessitam de orientações e acompanhamento que as auxiliem na construção de sua própria identidade e sexualidade (Wusthof, 1994). Pode-se dizer que a sexualidade se expressa no indivíduo na infância, modificando-se de acordo com o desenvolvimento do corpo e da mente do mesmo. Além disso, toda a base para o seu desenvolvimento está na infância; período este em que se alicerçam os fundamentos para a vivência de uma sexualidade sadia, prazerosa e significativa.
} 
autêntica: a procura mesmo da beleza interpessoal, a criação de um erotismo significativo do amor. (p. 111).

$\mathrm{Na}$ atualidade, os pais eximem-se da responsabilidade de educar sexualmente os filhos por acreditarem que eles são jovens demais para falar sobre o assunto. Para diversos adultos, a sexualidade é um assunto proibido para crianças e adolescentes de pouca idade e assim evitam discutir com eles os questionamentos relacionados ao tema. Vittelo (1997) alega que nossa sociedade vincula a prorrogação da comunicação aberta da sexualidade com os jovens para um futuro relativamente longínquo, pois, conforme mencionado anteriormente, muitas pessoas consideram a sexualidade exclusivo dos adultos.

Nesse sentido, é necessário que os adultos reconheçam que independente da idade, a sexualidade é uma característica experimentada por todo o ser humano e as dúvidas dos jovens necessitam ser esclarecidas e discutidas, de maneira clara e objetiva para que eles possam vivenciar a sua sexualidade de forma digna e responsável. Trindade \& Bruns (1999) afirmam que essa mesma sociedade, a qual tem como prática o deixar "para o amanhã" as orientações acerca da sexualidade, subsidia o exercício da sexualidade dos adolescentes com consequências ruins ou indesejadas, como uma gravidez precoce ou a infecção por uma agente sexualmente transmissível.

Há, também, na ausência de educação sexual, por parte dos pais da sociedade e até mesmo das instituições educacionais, a impressão de que a sua abordagem possa vir a estimular e antecipar cada vez mais a prática sexual dos adolescentes. Conforme salientam Trindade \& Bruns (1999), uma das grandes barreiras para a educação sexual na esfera familiar refere-se ao receio de despertar nos jovens o início da sua vida sexual. Ao contrário do que se propaga, a educação sexual não estimula e nem antecipa a atividade sexual entre os jovens. Já é reconhecido que a educação sexual contribui para atrasar a vida sexual dos adolescentes, uma vez que, esclarecidos tendem a ser mais responsáveis e a adiar o início da vida sexual (GUIMARÃES, 2003). Investigações, como a de Ramiro \& Matos (2008), sugerem que a atitude parental positiva em relação à sexualidade, bom relacionamento e a percepção de supervisão parental influenciam no adiamento da primeira experiência sexual dos filhos e na redução de gravidez não planeada.

No estudo de Sousa et al. (2006) sobre a influência de elementos culturais no contexto familiar e o comportamento sexual do adolescente realizado com a família de uma adolescente, foi constatado que o diálogo entre os pais e a filha era restrito e não existia abertura para conversas sobre questões relacionada a sexo e sexualidade. Os pais da adolescente, embasados na crença de que a conversa sobre sexo poderia induzir a adolescente a praticá-lo, procuraram preservar o silêncio sobre o assunto. Contudo, desprovida de orientações ou baseada em informações inadequadas a adolescente vivenciou uma gravidez precoce e indesejada. Segundo as autoras do estudo, somente após a percepção tardia de que a filha adolescente iniciou a vida sexual, foi que a mãe passou a conversar com ela sobre esse assunto, e ainda assim, a conversa se restringia a orientações superficiais sobre prevenção da gravidez.

Este estudo é um exemplo de que a falta de orientação e ausência de diálogo relativo à sexualidade no seio da família, tende a expor os adolescentes à prática do sexo inseguro e a gravidez precoce e indesejada, doenças sexualmente transmissíveis, sentimentos de vergonha e culpa. Para Gherpelli (1996), a possibilidade de contágio de doenças sexualmente transmissíveis e o aumento de gravidez na adolescência são que reforçam a hipótese de que a desinformação, a 
repressão, o silêncio, o medo e outros sentimentos negativos limitam as escolhas dos adolescentes. Sendo assim, faz-se necessário que a família e todos que participam da vida das crianças e adolescentes tenham em mente que as informações oferecidas por meio da educação sexual emancipatoria, visam a fornecer reflexões para que elas tenham discernimento do que é certo e errado, positivo e negativo e tenham conhecimento de medidas preventivas para promoção da saúde e do autocuidado. Cabe salientar que o desenvolvimento da educação sexual não visa a promover a abstinência sexual ou postergar o início da vida sexual entre os jovens, mas, sim, na formação da autoconsciência e no resgate do indivíduo enquanto sujeito de suas ações, para que seja livre para decidir, com responsabilidade, a hora certa para que a sexualidade seja compartilhada com outro individuo por meio do sexo.

Outra barreira ao estabelecimento da educação sexual no ambiente familiar é o desconforto dos pais em abordar o tema. Os pais ainda se sentem tímidos e incomodados em tratar do assunto e consequentemente optam pela omissão de informações e por atitudes repressoras para tentar conter as dúvidas e ansiedades dos filhos acerca do assunto. Tal atitude pode está relacionada ao fato dos pais não terem vivenciado uma educação sexual emancipatória e acabam, portanto, reproduzindo os valores que lhes foram impostos ou oportunizados por outra geração, perpetuando a deseducação sexual. O estudo desenvolvido por Almeida \& Centa (2009) no município de Toledo, Paraná, cujo objetivo foi identificar como a família vivencia a educação sexual dos filhos adolescentes, mostrou que os pais investigados, em geral, revelam que uma das razões pela qual sentem dificuldades em abordar o assunto, é a maneira como foram educados. Segundo os pais investigados, a educação recebida teria deixado marcas negativas que estavam presentes até o momento, o que dificulta a comunicação relacionada à sexualidade com os filhos.

Nesse sentido, é evidente que a falta de preparo dos pais para falar sobre o assunto com os filhos é devido à história de repressão que existe em torno dela, repassado de geração para geração. Pondera-se, contudo, que a sexualidade sempre foi um tema delicado, imerso de tabus, resistências e preconceitos, e nem todos os pais tiveram acesso a essas informações ao longo da sua vida em função da não educação que tiveram na juventude. Para Costa (1986), pais que tiveram uma educação extremamente repressiva e autoritária, entram em conflito com seus filhos adolescentes, por muitas vezes, não concordarem com suas ideias, gerando um clima tenso.

Esse fato demonstra a necessidade dos pais terem acesso a um processo de educação sexual emancipatório para que possam refletir sobre suas crenças, rever seu posicionamento e reformular conceitos equivocados e preconceituosos acerca da sexualidade. Para que os pais possam desvincular a sexualidade de estereótipos e tabus e desta forma oferecer uma boa educação sexual aos filhos é fundamental que revisem suas dificuldades por meio de leituras, reflexões e discussões sobre o tema. Assim, será possível informar e orientar seus filhos de forma mais positiva e isenta de preconceitos e atitudes anti-sexualidade. Além disso, é necessário que os pais repensem valores e atitudes repressivas que estão enraizados por causa da influência da educação sexual ao qual foram submetidos. Essa mudança segundo Suplicy (1983), depende que se crie um ambiente familiar sem repressões, onde qualquer assunto a respeito da sexualidade não seja proibido, e as informações sejam honestas, verdadeiras e naturais.

Apesar destas constatações, nem sempre os pais estão dispostos a assumir suas responsabilidades para com o desenvolvimento de uma educação sexual emancipatória com seus filhos ou muitos pais não possuem conhecimento, habilidades ou competências para colocar essa 
educação em prática. Nesse sentido, a escola surge como um espaço propício e privilegiado para o desenvolvimento de uma educação sexual emancipatória (VITIELLO, 1997). Nas escolas, a educação sexual deve ser viabilizada, por meio de orientações sexuais em forma de tema transversal, estando, inclusive, inserida nos Parâmetros Curriculares Nacionais (PCN). Nos PCNs há a premissa de que a sexualidade é uma questão social e que, portanto, deve ser trabalhada tanto na família como na escola, porém de maneira dinâmica e global, ou seja, respeitando a diversidade de crenças, de costumes e de valores próprios de cada cultura (BRASIL, 1997).

\section{A escola como espaço propício para o desenvolvimento de uma educação sexual emancipatória}

Os pais devem estar cientes de que é imprescindível, mas não exclusiva, a atuação da escola no processo de educação sexual emancipatória dos seus filhos, pois a escola é uma das instituições sociais que tem a função de possibilitar a construção de conhecimentos condizentes com a vida. Entretanto, a família não deve delegar apenas a escola a esta função. É importante lembrar que os pais são os primeiros educadores sexuais dos filhos, pois compete à família, a qual é uma instituição social permanente na vida do indivíduo, a grande parcela de responsabilidade na formação dos jovens (BIÉ et al, 2006).

Para Almeida (2005), é de extrema importância que as questões correlatas à sexualidade sejam tratadas na escola, mas há que existir uma efetiva parceria com os pais. É necessário que a educação sexual inicie em casa e seja complementada na escola, para que possa suprir as carências e dificuldades da família em relação ao tema. Em princípio, acreditava-se que as famílias apresentavam resistência à abordagem dessas questões no âmbito escolar, mas atualmente sabe-se que os pais reivindicam a orientação sexual nas escolas, pois reconhecem não só a sua importância para crianças e jovens, como também a dificuldade de falar abertamente sobre esse assunto em casa.

Os professores, independente da área de formação, devem contribuir para que os tabus e preconceitos ligados à sexualidade sejam excluídos ou no mínimo suavizados e que o conhecimento geral dos educandos sobre o assunto seja melhorado para que cada indivíduo viva de forma apropriada e singular sua sexualidade. Para Suplicy (1983), o objetivo da educação sexual na escola consiste em colocar professores com um preparo adequado para ajudar os educandos a superarem suas dúvidas, ansiedades e angústias em relação à temática.

Apesar da importância da escola realizar um trabalho de educação sexual junto aos alunos, observa-se que são poucas as escolas que incluem em suas práticas pedagógicas a discussão de um tema tão importante e necessário como à sexualidade (BRITO \& CARDOSO, 2009). Para Garcia (2005), a abordagem da sexualidade nas escolas é, de uma forma geral, muito difícil; os professores resistem muito em tomar para si qualquer responsabilidade "intencional" de educar sexualmente os adolescentes. O estudo de Bomfim (2009), por exemplo, numa pesquisa com dez alunos de uma escola pública em Salvador-BA revela que $50 \%$ dos alunos pesquisados afirmaram que a sexualidade não é abordada na escola; $30 \%$ pontuaram que é abordado "algumas vezes", $10 \%$ afirmaram que é abordado "de forma superficial e pouco falado" e os outros $10 \%$ ressaltaram que abordaram "apenas uma vez". Esses dados mostram que apesar do Ministério da Educação ter incluído nos PCNs a abordagem da sexualidade nos currículos das diversas áreas do conhecimento, como um dos temas transversal, este assunto ainda é pouco trabalhado na escola ou trabalhado de forma insatisfatória. 
As dificuldades dos professores em realizar a educação sexual têm sido evidenciadas em vários estudos (PIASENTIM, 2009; GARCIA, 2005; BOMFIM, 2009). A bibliografia na área tem apontado que esta prática se fundamenta em vários motivos, tais como: timidez, insegurança para debater o tema, falta de preparo oriundo das lacunas de formação docente; da reprodução da repressão sexual a qual os educadores foram submetidos e até mesmo da ideia de que o tema deva ser tratado exclusivamente pela família. Maistro et al. (2009), por exemplo, evidenciam que a abordagem da sexualidade nas escolas não passa de uma visão reducionista do corpo desvinculada da realidade do aluno. De acordo com os autores, a educação sexual, quando abordada nas escolas, na maioria das vezes, se reduz a uma perspectiva higienista, que reduz 0 corpo aos conceitos de assepsia, controle e prevenção; e ao mero aprendizado biológico e anatômico do corpo reforçando a ideia da sexualidade ligada à reprodução. O estudo de Melo \& Santana (2005), que aborda os valores e condutas relativas à sexualidade entre universitários do curso de Ciências Biológicas da UEFS, corrobora este fato. Neste estudo, 70\% dos universitários afirmaram que as discussões sobre sexualidade no espaço escolar é basicamente voltada para questões biológicas.

Nesse sentido, é necessário que a escola, enquanto instituição educacional reconheça que a educação sexual emancipatória não se restringe ao mero aprendizado dos aspectos anatômicos e biológico do corpo humano. Compreende-se que a abordagem da sexualidade em sala de aula extrapola a visão biológica e a descrição fragmentada e fria do corpo. Discutir essa temática significa possibilitar a discussões de emoções e valores ligadas a ela.

Para isso, é igualmente necessário reconhecer que primeiramente, tratar da sexualidade na escola requer uma reeducação dos profissionais da educação que estão em contato direto com os adolescentes. De acordo com Gagliotto \& Lembeck (2011), essa reeducação deve buscar, por meio de fundamentação teórica e científica, discutir e debater a sexualidade humana numa dimensão histórica, antropológica, filosófica, biológica, psicológica e pedagógica, a fim de compreender e ter um relacionamento que possa colaborar com o seu desenvolvimento. Portanto, se faz necessário que se invista na formação dos docentes para que os mesmos possam lidar de maneira coerente com as dúvidas e problemas que surgem durante 0 processo de ensino-aprendizagem. Embora seja primordial docentes capacitados para o trabalho de educação sexual, a produção acadêmica tem revelado o despreparo dos professores diante do tema (BOMFIM, 2009; JARDIM e BRÊTAS, 2006; RAMIRO \& MATOS, 2008). A capacitação de educadores, em cursos de formação inicial e continuada de professores, para lidar com a sexualidade dos adolescentes ainda não ter chegado as instituições escolares em termos de realidade brasileira.

Atualmente os professores podem, por exemplo, procurar facilmente, na rede mundial de computadores, por cursos de capacitação relativamente flexíveis, como aqueles ligados a pósgraduações lato sensu, cursos de curta duração oferecidos no âmbito de programas ou projetos de extensão vinculados a instituições de ensino superior, cursos de curta duração oferecidos na modalidade de ensino à distância, dentre outros. Além disso, especialistas com capacitação comprovada em educação sexual podem promover uma constante reciclagem de conhecimentos dos professores, servindo de suporte técnico na orientação de problemas educativos.

Para essa temática, políticas de apoio a projetos e programas de capacitação ou orientação sexual têm sido observadas. Apenas a título de exemplificação, vale mencionar sobre o lançamento de editais abertos, pela Secretaria Geral da Presidência da República, a instituições públicas ou não governamentais para seleção de projetos de prevenção e combate à homofobia, 
através da prestação de assessoria jurídica e psicossocial às vítimas, da orientação e encaminhamento de denúncias, da capacitação em direitos humanos e da mediação e conciliação de conflitos. A partir de 2005, o Ministério da Educação passou a lançar editais públicos para seleção de projetos de capacitação de profissionais de educação em temas relativos à "orientação sexual" e à "identidade de gênero". A Secretaria Especial de Direitos Humanos, por seu lado, tem apoiado a criação de dezenas de centros de referência em direitos humanos com o objetivo de prevenir e combater a violência e a discriminação homofóbicas, dando apoio jurídico e psicossocial às vítimas. Espalhados por todo o país, muitos desses centros estão sendo implantados em organizações do movimento LGBT e outros em secretarias estaduais e municipais.

Apesar disso, é igualmente importante destacar que ações e propostas isoladas, como palestras ou cartilhas, não atingem os adolescentes de forma eficiente, pois somente os sensibilizam, mas não colaboram para que ocorram mudanças positivas e significativas. Receitas prontas e palestras uma vez ao ano são atividades que negam a participação e o diálogo, pois, no caso, os adolescentes apenas recebem as informações, continuando com dificuldades para superar seus conflitos.

Conforme discutido por Gagliotto \& Lembeck (2011), é necessário promover, organizar e planejar atividades sistemáticas que ocorram durante todo o ano letivo. Por meio destas atividades, deve-se buscar a manutenção de um processo permanente de ação e reflexão, desenvolvendo atividades em que os adolescentes possam sugerir os temas a serem discutidos, partindo da realidade e de seus interesses. As atividades em grupos, organizadas de maneira prazerosa e com a participação dos adolescentes, discutindo de forma ativa, com questionamentos, troca de informações, de forma respeitosa, livre e enriquecedora, são uma das alternativas que se tem para trabalhar de forma emancipatória a educação sexual.

É pertinente mencionar que a omissão da educação sexual, por parte da família e da escola, produz efeitos diversos, as quais refletem prejuízos para a qualidade de vida dos adolescentes como medo, vergonha, esvaziamento, insegurança, infelicidade, tédio, frustração, gravidez na adolescência, contaminações por doenças sexualmente transmissíveis entre outros.

\section{CONCLUSÃO}

Baseado no exposto, conclui-se que os estudos selecionados apontam para a necessidade do estabelecimento da educação sexual emancipatória dentro do contexto familiar e escolar, para assim informar, esclarecer e orientar os adolescentes quanto a práticas seguras da sexualidade. A participação dos pais e professores é relevante para que os adolescentes assumam seu corpo e sua sexualidade com atitudes positivas, livre de medo, culpa e preconceito.

Os referenciais consultados evidenciam que tanto a família, quanto a escola têm-se mantido omissas no que se refere à educação sexual emancipatória. Os pais ainda esbarram em barreiras para o estabelecimento da referida educação sexual, pelo valor negativo atribuído ao sexo, por acreditarem que os filhos não são seres sexuados e/ou por considerarem que o diálogo antecipa a prática do ato sexual.

Por conseguinte, a dificuldade em abordar a temática na estrutura familiar, tem apontado a escola como solução para essa problemática, por meio da educação ou orientação sexual. Entretanto, nas escolas, a educação sexual não tem abarcado as ansiedades dos 
adolescentes. Esta tem sido conduzida de forma limitada, aliada apenas aos aspectos biológicos e reprodutivos dos indivíduos, negando assim, toda a amplitude prazerosa e benéfica que a mesma propicia. Por fim, salienta-se que é importante que a educação sexual seja iniciada em casa e seja complementada na escola, para que possam suprir o despreparo e as dificuldades dos pais em relação ao tema e ajudar os adolescentes a enfrentar as dúvidas e ansiedades.

\section{REFERÊNCIAS BIBLIOGRÁFICAS}

1. ALMEIDA, A. C. C. H., CENTA, M. L. A família e a educação sexual dos filhos: implicações para a enfermagem. Acta Paulista de Enfermagem, v. 22, n. 1, p. 71-76, 2009.

2. ALMEIDA, D. S. O.; COSTA, R .L.; SILVA , T. M. Chega de tabu! A sexualidade sem medos e sem cortes. 2005. Disponível em <http://www.unesp.br/prograd/PDFNE2005/artigos/capitulo\%201/ch. Acesso em: 12 maio 2011.

3. ARAÚJO, M. L. M. Aspectos psicossociais da adolescência. In: RIBEIRO, M. (Org.). Educação sexual: novas ideias, novas conquistas. Rio de janeiro: Rosas dos Tempos, 1993. p. 113119.

4. BERNARDI, M. A Deseducação Sexual. São Paulo: Summus, 1985.

5. BIÉ, A. P. A.; DIÓGENES, M. A. R.; MOURA, R. F. Planejamento familiar: o que os adolescentes sabem sobre este assunto? Revista Brasileira em Promoção da Saúde, v. 19, n. 3, p. 125-130. 2006.

6. BOMFIM, S. S. Orientação sexual na escola: tabus e preconceitos, um desafio para a gestão. Monografia (Pedagogia), Universidade do Estado da Bahia, Salvador, 2009.

7. BRASIL. Parâmetros Curriculares Nacionais: pluralidade cultural, orientação sexual. Brasília, DF: Secretaria de Educação Fundamental, 1997.

8. BRITO. D. C.; CARDOSO. I. P. Escola e orientação sexual: desafios à prática de um trabalho contínuo. Cadernos IAT, v. 2, n. 1, p. 62-82, 2009.

9. CHAVES, G. B.; QUEIROZ, E.; GERRA, L.B. Apontamentos para Trabalho em Educação Sexual nas Escolas. Anais do 70 Encontro de Extensão da Universidade Federal de Minas Gerais. Belo Horizonte, 2004.

10. COSTA, M. Sexualidade na adolescência: dilemas e crescimento. 8. ed. São Paulo: L \& PM Editores, 1986.

11. DUNAIGRE, P. A criança é um sujeito sexuado, mas não um objeto sexual (2003).

Disponível em:

http://www.revistacontinente.com.br/index.php/component/content/article/1126.html.

Acesso em: 4 ago. 2013.

12. ECOS - Estudos e Comunicação em Sexualidade e Reprodução Humana. Promover a educação sexual nas escolas. Disponível em: http://www.polis.org.br/uploads/623/623.pdf. Acesso em: 4 ago. 2013.

13. GAGLIOTTO, G. M. A educação sexual da criança e a pedagogia da infância: matrizes institucionais, disposições culturais, potencialidades e perspectivas emancipatórias. 2009. 260 p. Tese (Doutorado em Educação) - Faculdade de Educação, Universidade Estadual de Campinas, Campinas, 2009.

14. GAGLIOTTO, G. M.; LEMBECK, T. Sexualidade e adolescência: a educação sexual numa perspectiva emancipatória. Educere et Educare - Revista de Educação, v. 6, n. 11, p. 1-18, 2011. 
15. GARCIA, A. M. A Orientação Sexual na Escola: Como os professores, alunos e pais percebem a sexualidade e o papel da escola na orientação sexual. Dissertação (Mestrado), Universidade Estadual Paulista, Bauru, São Paulo, 2005.

16. GHERPELLI, M. H. B. V. A Educação preventiva em sexualidade na adolescência. São Paulo: FDE, 1996.

17. GIR, E.; NOGUEIRA, M. S.; PELÁ, N. T. R. Sexualidade humana na formação do Enfermeiro. Revista Latina-Americana de Enfermagem, v. 8, n. 2, p. 33-40, 2000.

18. GONÇALVES, R. C.; DIONÍZIO, A. F.; RESENDE, I. L. M. Diálogo acerca da sexualidade entre pais e filhos na concepção dos adolescentes. UEG em Revista, v. 1, p. 27-49, 2010.

19. GUIMARÃES, A. M. A. N.; VIEIRA, M.J.; PALMEIRAS, J. A. Informações dos Adolescentes sobre Métodos Anticoncepcionais. Revista Latina-Americana de Enfermagem, v. 11, n. 3 , p. 293-298, 2003.

20. HUERRE, P. A adolescência como herança: de uma geração a outra. Campinas - SP: Editora Papirus, 1998.

21. JARDIM, D.P. e J.R.S. BRÊTAS. Orientação sexual na escola: a concepção dos professores de Jandira - SP. Revista Brasileira de Enfermagem, v. 59, n. 2, p. 157-162, 2006.

22. JESUS, R. M. B. Implicações da ação docente sobre as questões de sexualidade e gênero na escola. Revista Faced. Salvador, v. 11, p. 189-199, 2007.

23. MAISTRO, V.I.A.; ARRUDA, S.M.; JUNIOR, A.L. O papel do professor em um projeto de educação sexual. In: ENPEC, 7, 2009, Florianópolis. Anais VII ENPEC, Florianópolis: ABRAPEC, 2009.

24. MEAD, M. Adolescência y cultura en Samoa. Buenos Aires: Editora Abril, 1945.

25. MEDRADO, Benedito A masculinidade na propaganda televisiva brasileira (dissertação mestrado em Psicologia Social). São Paulo: PUC/SP, 1997.

26. MEDRADO, B.; LYRA, J. Por uma matriz feminista de gênero para os estudos sobre homens e masculinidades. Estudos Feministas, v. 16, n. 3, p. 809-840, 2008.

27. MELO, A. S. A.; SANTANA, J. S. Sexualidade: concepções, valores e conduta entre universitários de Biologia da UEFS. Revista Baiana de Saúde Pública, v. 29, n. 2, p. 149159, 2005.

28. MOIZÉS, J. S; BUENO, S. M. V. Compreensão sobre sexualidade e sexo nas escolas segundo professores do ensino fundamental. Revista Escola em Enfermagem, v. 44, n. 1, p. 205212, 2010.

29. NASCIMENTO, M.; FONSECA, V. Da "anatomia como destino" ao "cruzamento das fronteiras": gênero e sexualidade no mundo de Almodóvar. InCID: Revista de Ciência da Informação e Documentação, v. 2, n. 2, p. 67-76, 2011.

30. NUNES, C. A. Filosofia, sexualidade e educação: as relações entre os pressupostos éticosociais e histórico-culturais presentes nas abordagens institucionais sobre a educação sexual escolar. Tese (Doutorado em Educação). Faculdade de Educação da Universidade Estadual de Campinas, 1996.

31. OlIVEIRA, D. C.; GOMES, A. M. T.; PONTES, A. P. M.; SALGADO, L. P. P. Atitudes, sentimentos e imagens na representação social da sexualidade entre adolescentes. Revista de Enfermagem, v. 13, n. 4, p. 817-23, 2009.

32. OMS - Organzación Mundal de La Salud. Prevención de la transmisión sexual del Virus de la Immnodeficiencia Humana. Serie OMS sobre el SIDA, v. 6, n. 1, 1990. 
33. PIASENTIM, R. L. de A. Sexualidade e adolescência nas 5ạs séries. 2009. Disponível em: http://www.diaadiaeducacao.pr.gov.br/portals/pde/arquivos/2273-8.pdf. Acessado em: 17 jun. 2011.

34. RAMIRO, I; MATOS, M.G. Percepções de professores portugueses sobre educação sexual. Revista de Saúde Pública, v. 42, n. 4, p. 684-692, 2008.

35. RAPPAPORT, C. Encarando a adolescência. 8 ed. São Paulo: Ática, 2001.

36. SANTOS, M. A. Orientação sexual no 1 ㅇ e 2 ㅇ ciclos do ensino fundamental: uma realidade distante? Monografia (Pedagogia) - Universidade Federal do Rio Grande do Norte, 2001.

37. SOUSA, L. B., FERNANDES, J. F. P., BARROSO, M. G. T. Sexualidade na adolescência: análise da influência de fatores culturais presentes no contexto familiar. Acta Paulista de Enfermagem, v. 19, n. 4, p. 408-413, 2006.

38. SOUZA, H. P. Convivendo com seu sexo (Pais e Professores). 2 ed. São Paulo: Paulinas, 1991.

39. SUÁREZ, A. D. Crise de identidade na adolescência: breve análise e implicações para a práxis religiosa segundo a teoria de Erik Erikson. Acta Científica - Ciências Humanas, v. 2, n. 9, p. 31-38, 2005.

40. SUPLICY, M. Conversando sobre sexo. Petrópolis, RJ: Vozes, 1983.

41. TIBA, I. Adolescência: o despertar da sexualidade. São Paulo: Gente, 1994.

42. TRINDADE, E.; BRUNS, M. A. T. Adolescentes e paternidade, um estudo fenomenológico. Ribeirão Preto: Holos, 1999.

43. TUCKMANTEL, M. M. A educação sexual: mas qual? Diretrizes para formação de professores em uma perspectiva emancipatória. Tese (Doutorado em Educação). Faculdade de Educação da Universidade Estadual de Campinas, 2009.

44. VASCONCELOS, N. Os dogmatismos sexuais. Rio de Janeiro: Paz e Terra, 1971.

45. VITIELLO, N. Quem Educa o Educador: Um Manual para Jovens, Pais e Educadores. São Paulo: Inglu, 1997.

46. WUSTHOF, R. Descobrir o sexo . São Paulo: Ática, 1994. 